\title{
Morpho- agronomical Characterization of Taro (Colocasia esculenta) accessions in Ethiopia
}

\author{
Tewodros Mulualem Beyene \\ Jimma Agricultural Research Centre, Department of Root, Fruit and Vegetables Crops Research, P.O.Box, 192, Jimma, Ethiopia
}

Email address:

tewodros74@yahoo.com (T. Mulualem Beyene)

To cite this article:

Tewodros Mulualem Beyene. Morpho- Agronomical Characterization of Taro (Colocasia esculenta) Accessions in Ethiopia, Plant. Vol. 1, No. 1, 2013, pp. 1-9. doi: 10.11648/j.plant.20130101.11

\begin{abstract}
One hundred accessions of taro (Colocasia esculenta) were tested at Jimma Agricultural Research Center during the 2011 growing season by using 10 x10 simple lattice design with two replications. The objectives of the study were to assess the nature and extent of diversity with in collected accessions based on key morphological descriptors and evaluate the accessions based on yield and yield related traits. Data on 17 qualitative and 13 quantitative traits were measured. Both sets of data collected were subjected to multivariate analysis using principal component (PCA), cluster analysis and of analysis of variance to determine the variability among accessions. The results of PCA based on qualitative traits reveled that characters have large contribution to the variability. The two-dimensional plot of the first two PCs showed a separation between accessions of big sized. Cluster analysis based on qualitative characters indicated the formation of seven clusters and existence of variability, based on their foliar and subterranean traits. Shannon-Weaver diversity index $(\mathrm{H}=0.27)$ showed that low levels of diversity existed among 100 C. esculenta based on the frequency of phenotypic characters that were considered. The analysis of variance for quantitative traits showed that number of active leaves/plant, petiole length and maximum horizontal distance highly significance differences exists for majority of characters studied and also path coefficient analysis at genotypic level showed that there are a number of characters exerting a maximum direct positive effect on fresh tuber yield suggesting that these characters are good contribution to the fresh root yield in taro. Overall, this study indicated that taro accessions collected from south and southwestern Ethiopia have an enormous wealth of traits variation for qualitative and quantitative characters, indicating huge potential for its genetic improvements through selection and hybridization. Therefore, selections based on these characters are efficient to maximize the fresh root yield and the genetic improvement of the crop.
\end{abstract}

Keywords: Cluster, Genetic Diversity, Principal Component, Taro

\section{Introduction}

Taro (Collocasia esculenta) is an important food crop in tropical areas of Africa, Asia and Latin America [1]. It is particularly important for food security since many tropical areas often experience unfavorable environmental conditions. In Ethiopia, Taro has been cultivated mainly and extensively in dense populated and high rainfall areas of South, Southwest and Western parts of the country. Its use as a potential crop in Ethiopians has been appreciated since 1984 famine [1]. In some areas, it used as fill seasonal food gaps when other crops are not in the field [2].

Farmers give many reasons why they cultivate taro. According to [3], Taro is cultivated because of produce reasonable amounts of yield when other crops hardly grow, resistant to disease and pests, ease of ecological adaptation and utilization of different purposes. In South and Southwestern Ethiopia, for instance, farmers cultivated different taro cultivars were distinguished one from the other on the bases of morphological and phonologic characters. However, the existence of different vernacular names for the same cultivar of the species, or vice versa has created problems to classify accessions while avoiding duplicates. Genetic diversity refers to the variation of genes within species. Diversity of Taro here defined as the presence of different accessions found in south and Southwest Ethiopia.

In South and South-west Ethiopia large pool of taro germplasm is found in farmers' field and forest areas. Nevertheless, this germplasm is being lost because of replace the crop by cereals (high value), drought and human interference such as deforestation. Therefore, there is need to characterize, conserve and maintain the germpalsm to serve as a source of desired genotypes for further breeding pur- 
poses and to reduce further genetic erosion [4]. In Ethiopia, some taro germplasm collection and conservation works have been started by agricultural research centers. However, like yam taro is distributed across diverse agrogeographical areas of the country that have not been adequately represented [5]. Moreover, the collected accessions have not been properly evaluated and their attribute remains unknown by breeders. So, detailed descriptions of accessions based on morpho-agronomical characters have tremendous impact on the conservation and genetic improvement of the crop. Previous to this study, information on these aspects scanty to plan an effective breeding program. The present study was, therefore, intended to assess the nature and extent of genetic diversity of taro in Ethiopia.

\section{Materials and Methods}

\subsection{Description of the Study Area}

The experiment was conducted at Jimma Agricultural Research Center located at $366 \mathrm{~km}$ south west of Addis Ababa. The site is situated at latitude 7o 46' $\mathrm{N}$ and longitude $360 \mathrm{E}$ with an altitude of 1753 m.a.s.l. The soil of the area is Eutric Nitosole with a $\mathrm{pH}$ of 5.3. The area receives mean annual rainfall of $1432 \mathrm{~mm}$ with maximum and minimum temperature of $29.20 \mathrm{C}$ and of $8.900 \mathrm{C}$, respectively. These environmental conditions are conducive for production of Colocasia esculenta.

\subsection{The Accessions Evaluated}

The total of 100 Colocasia esculenta accessions was considered in this study. The accessions were collected from different parts of Ethiopia, during 2008 - 2011 by Jimma Agricultural Research Center. The collections covered diverse agro-ecologies with an altitude ranges from 1130-2340 m.a.s.1, representing one of the major taro production areas in the country.

\subsection{Experimental Design and Management}

The experiment was laid out in 10 X10 simple lattice design using $10 \mathrm{~m} \times 10 \mathrm{~m}$ plots with two replications. Single row plot, with each row $10 \mathrm{~m}$ long with spaced $0.75 \mathrm{~m}$ between rows and $0.5 \mathrm{~m}$ between plants within a row was arranged providing 13 plants per row. Corms of the same size were used as a planting material and planted on a ridge during onset of rainy season (early April 2011). One month after planting, after the crop was well established, the plants were earthed up. Cultivation and weeding were carried out when necessary.

\subsection{Morphological Data Collection}

Descriptor of taro (Colocasia esculenta) developed by [6] were followed for data collection. There were two sets of data's (qualitative and quantitative) collected for assessing the diversity and to find key morphological traits in taro cultivars. In regarding to the qualitative traits, only the first replication of the experiment was considered, whereas, for quantitative characters the entire replications were considered. Among the descriptor developed by [6] to characterize taro cultivars, 17 qualitative and 13 quantitative traits were used, most of which were distinguished as highly heritable traits and were used for analysis. Both foliar and subterranean data's were considered. For foliar traits, scored at five months after planting, while, subterranean traits were evaluated at harvest ( 8 months). Most of the data (qualitative and quantitative traits) were recorded on individual plant basis using sample averages of six plants selected at random from the row.

Statistical Analysis

Data of quantitative characters were subjected to analysis of variance (ANOVA) as suggested by [7] using [8] to examine the presence of statistically significant differences among genotypes for these characters. Least Significant Difference (LSD) was employed to identify genotypes that are significantly different from each other. The analysis of Variance (ANOVA) (Table 2) was made using model for simple lattice design

$$
\text { yijklm }=\mu+t i+\beta i+\chi k+y l+\pi m+\Sigma_{i j k l m}
$$

Where, Yijklm $=$ response of $\mathrm{Y}$ trait from the ith accession, $j$ th replication, $\mu=$ Overall mean effects, $\mathrm{ti}=$ Effects of ith level of treatments, $\beta=$ Effects of $j$ th level of replication, $\chi \mathrm{k}=$ Effects of Kth level of blocks within replications (adjusted for treatments), $y l=$ Effects of lth level of intra block error, $\pi \mathrm{m}=$ Effects of the $\mathrm{mth}$ randomized complete block error and Óijklm= is a random error component.

Table 2. Frequency distribution and Shannon-Weaver diversity indices ('H') of 17 qualitative traits of Collocasia esculenta grown at Jimma.

\begin{tabular}{|c|c|c|c|c|}
\hline No. & Qualitative character & Index and description adopted & Frequency $(\%)$ & $H^{\prime}$ \\
\hline 1 & Leaf position & Horizontal Cup- shaped & $\begin{array}{l}73.0 \\
27.0\end{array}$ & 0.20 \\
\hline 2 & Leaf blade margin & Undulate Sinuate Other & $\begin{array}{l}83.0 \\
16.0 \\
1.0\end{array}$ & 0.17 \\
\hline
\end{tabular}




\begin{tabular}{|c|c|c|c|c|}
\hline 3 & Leaf blade margin color & Yellow or yellow green Green Other & $\begin{array}{l}42.0 \\
55.0 \\
3.0\end{array}$ & 0.51 \\
\hline 4 & Leaf blade color & Yellow Green Pink & $\begin{array}{l}24.0 \\
65.0 \\
11.0\end{array}$ & 0.30 \\
\hline 5 & Leaf blade color variegation & Present & 100 & 0.00 \\
\hline 6 & Leaf Vain pattern & Y-pattern & 100.0 & 0.00 \\
\hline 7 & Leaf main vain color & Yellow Green Other & $\begin{array}{l}14.0 \\
76.0 \\
10.0\end{array}$ & 0.25 \\
\hline 8 & Petiole Junction color & Yellow Green Purple & $\begin{array}{l}50.0 \\
6.0 \\
44.0\end{array}$ & 0.30 \\
\hline 9 & Petiole junction pattern & Small Medium & $\begin{array}{l}56.0 \\
44.0\end{array}$ & 0.24 \\
\hline 10 & Petiole color & Whitish Light green Green Purple & $\begin{array}{l}9.0 \\
17.0 \\
64.0 \\
10.0\end{array}$ & 0.36 \\
\hline 11 & Petiole basal- ring color & Green Other & $\begin{array}{l}41.0 \\
59.0\end{array}$ & 0.23 \\
\hline 12 & Corm skin surface & Smooth Fibrous & $\begin{array}{l}26.0 \\
74.0\end{array}$ & 0.20 \\
\hline 13 & Corm shape & Conical Round Cylindrical & $\begin{array}{l}48.0 \\
47.0 \\
5.0\end{array}$ & 0.30 \\
\hline 14 & Corm cortex color & Brown Purple Blackish & $\begin{array}{l}26.0 \\
11.0 \\
63.0\end{array}$ & 0.31 \\
\hline 15 & Corm flesh color & White Pink & $\begin{array}{l}55.0 \\
45.0\end{array}$ & 0.24 \\
\hline 16 & Root color & Brown & 100.0 & 0.00 \\
\hline 17 & Corm Branching & Un branched Branched & $\begin{array}{l}14.0 \\
86.0\end{array}$ & 0.14 \\
\hline \multicolumn{4}{|c|}{ Overall Mean } & 0.27 \\
\hline
\end{tabular}

The analysis of variance for all traits was carried out using [8] statistical computer packages. Least Significant Difference (LSD) was employed to identify genotypes that are significantly different from each other. Heritability in broad sense (h2B) and genetic advance as percent of means were calculated for all characters according to the method described by [9]. Phenotypic coefficient of variation (PCV) and genotypic coefficient of variation $(\mathrm{GCV})$ were estimated according to [10] while the Mahalanobi's generalized distance (D2) statistics [11] was used for clustering of genotypes by assessing the divergence between genotypes for the traits measured by using SAS software statistical package [8]. 


\section{Result and Discussion}

Agro-morphological variability of taro accessions based on qualitative characters using cluster and principal components analysis. Cluster analysis based on qualitative traits separated accessions using distance between cluster and UPGMA clustering, gave four major clusters and three individual cultivars, with distance between cluster ranging from 0.0-2.0. A dendrogram summarizing the existing genetic similarity among taro accessions based on qualitative agro-morphological characters is shown in Figure-1. The number of accessions belonging to each cluster varied from one in clusters III and IV to 55 in cluster V.

Cluster I consisted of 35 entries $(35.0 \%)$ of the total. Accessions grouped under this cluster have predominantly horizontal and cup- leaf position, undulate leaf blade margin, yellow and green leaf blade margin, yellow and green leaf blade, Y- shaped leaf vain pattern, yellow, green and purple petiole junction color, green and white green petiole basal- ring color, smooth and fibrous corm skin surface, conical and round corm shape, brown, purple and blackish corm cortex color and un-branched and branched corm.

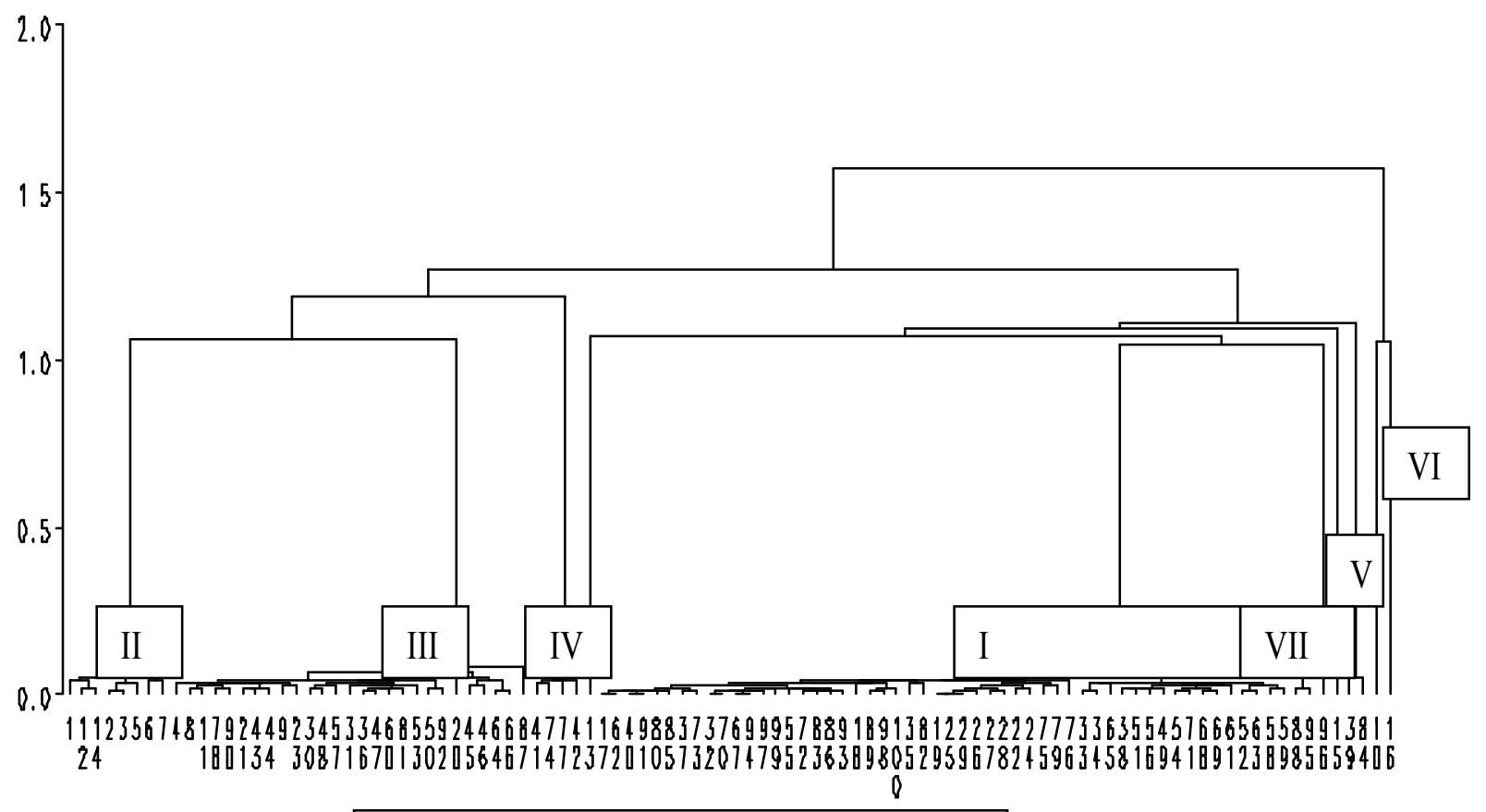

\section{Serial number of accessions}

Figure 1. Dendrogram showing relationship of 100 taro accessions based on Euclidian distance and UPGMA clustering using 17 qualitative traits.

Cluster-II and cluster-VI had two accessions. Accessions categorized in this cluster had cup- shaped leaf, undulate leaf blade margin, yellow or yellow green leaf blade margin color, yellow ,green leaf blade color, yellow leaf main vain color, brown root color, yellow and purple petiole junction color green and white green petiole basal- ring, fibrous corm skin surface, conical corm shape, and branched corm.

For instance, cluster $\mathrm{V}$ had the largest and consisted of 55 accessions $(55.0 \%)$ and accessions clustered in this group long basal ring length, horizontal leaf position, undulate leaf blade margin, yellow leaf blade margin, green leaf blade, Y- shaped leaf vain pattern, green and purple petiole junction color, green petiole basal- ring color, smooth corm skin surface. Likewise, cluster II and III are solitary clusters; each of these clusters contained only one (1\%) distinct accession.

The results of principal component analysis based on 17 qualitative traits also revealed the existence of diversity among the taro accessions used in this study. Ordination among accessions showed that the first seven principal components (PCs) had Eigen values greater than one and cumulatively accounted for $64.9 \%$ of variation (Table 1 ). The first component alone explained $13 \%$ of the total variation and was mainly associated with characters such as leaf vain color (LVC), corm skin surface (CSur), leaf shape (LS) and leaf blade margin color (LBMC). The second principal components (PCs) explained $11 \%$ of variation and were associated with corm branching $(\mathrm{CBr})$, corm skin surface (CSS), and leaf blade margin color (LBMc). The third principal components (PCS) explained $9.7 \%$ of the variation and were associated with leaf blade margin (LBM), petiole junction color (PJC) and corm skin surface (CSS). The fourth component was mainly associated with tuber surface texture (TST) and tuber flesh color (TFC) and had 9.3\% of the variation. The other principal components (PCs) covered $57 \%$ of the variation. 
Table 1. Eigen values, Variance, Cumulative variance and component scores of the first seven principal components for qualitative traits in 100 taro.

\begin{tabular}{|c|c|c|c|c|c|c|c|}
\hline & PCI & PC2 & PC3 & PC4 & PC5 & PC6 & PC7 \\
\hline Eigen value & 1.9466 & 1.6550 & 1.4505 & 1.3954 & 1.1899 & 1.0898 & 1.0124 \\
\hline Variance(\%) & 13.00 & 11.00 & 9.700 & 9.30 & 7.90 & 7.30 & 6.70 \\
\hline Cumulative (\%) & 1.30 & 24.00 & 33.70 & 43.00 & $\mathbf{5 0 . 9 0}$ & $\mathbf{5 8 . 2 0}$ & 64.90 \\
\hline Leaf shape & 0.330 & -0.466 & 0.058 & 0.036 & 0.067 & -0.101 & 0.133 \\
\hline Leaf blade margin & 0.138 & -0.182 & 0.287 & -0.289 & -0.548 & 0.010 & -0.145 \\
\hline Leaf blade margin color & -0.038 & 0.318 & -0.144 & -0.230 & -0.514 & -0.345 & -0.207 \\
\hline Leaf blade color & 0.080 & -0.236 & -0.585 & 0.125 & -0.178 & 0.137 & 0.190 \\
\hline Leaf blade color variegation & 0.098 & 0.013 & -0.580 & -0.211 & -0.099 & 0.078 & 0.037 \\
\hline Petiole junction color & 0.121 & -0.463 & 0.229 & -0.253 & -0.112 & 0.097 & -0.220 \\
\hline Leaf vain color & 0.435 & 0.244 & -0.203 & 0.048 & -0.020 & 0.130 & -0.381 \\
\hline Vain pattern & 0.107 & -0.092 & -0.012 & 0.026 & 0.168 & -0.809 & 0.171 \\
\hline Petiole color & -0.144 & -0.029 & -0.093 & -0.365 & 0.056 & -0.250 & -0.156 \\
\hline Petiole basal ring color & -0.547 & 0.182 & 0.085 & 0.072 & -0.156 & 0.035 & 0.112 \\
\hline Tuber surface texture & 0.081 & -0.054 & -0.083 & 0.538 & -0.294 & -0.293 & -0.071 \\
\hline Tuber shape & -0.105 & -0.070 & -0.221 & -0.356 & 0.439 & -0.096 & -0.293 \\
\hline Tuber flesh color & -0.250 & -0.117 & -0.042 & 0.280 & 0.113 & -0.068 & -0.661 \\
\hline Corm skin surface & 0.434 & 0.340 & 0.193 & 0.169 & 0.151 & 0.017 & -0.188 \\
\hline Corm branching & 0.224 & 0.373 & 0.105 & -0.271 & 0.078 & -0.041 & 0.242 \\
\hline
\end{tabular}

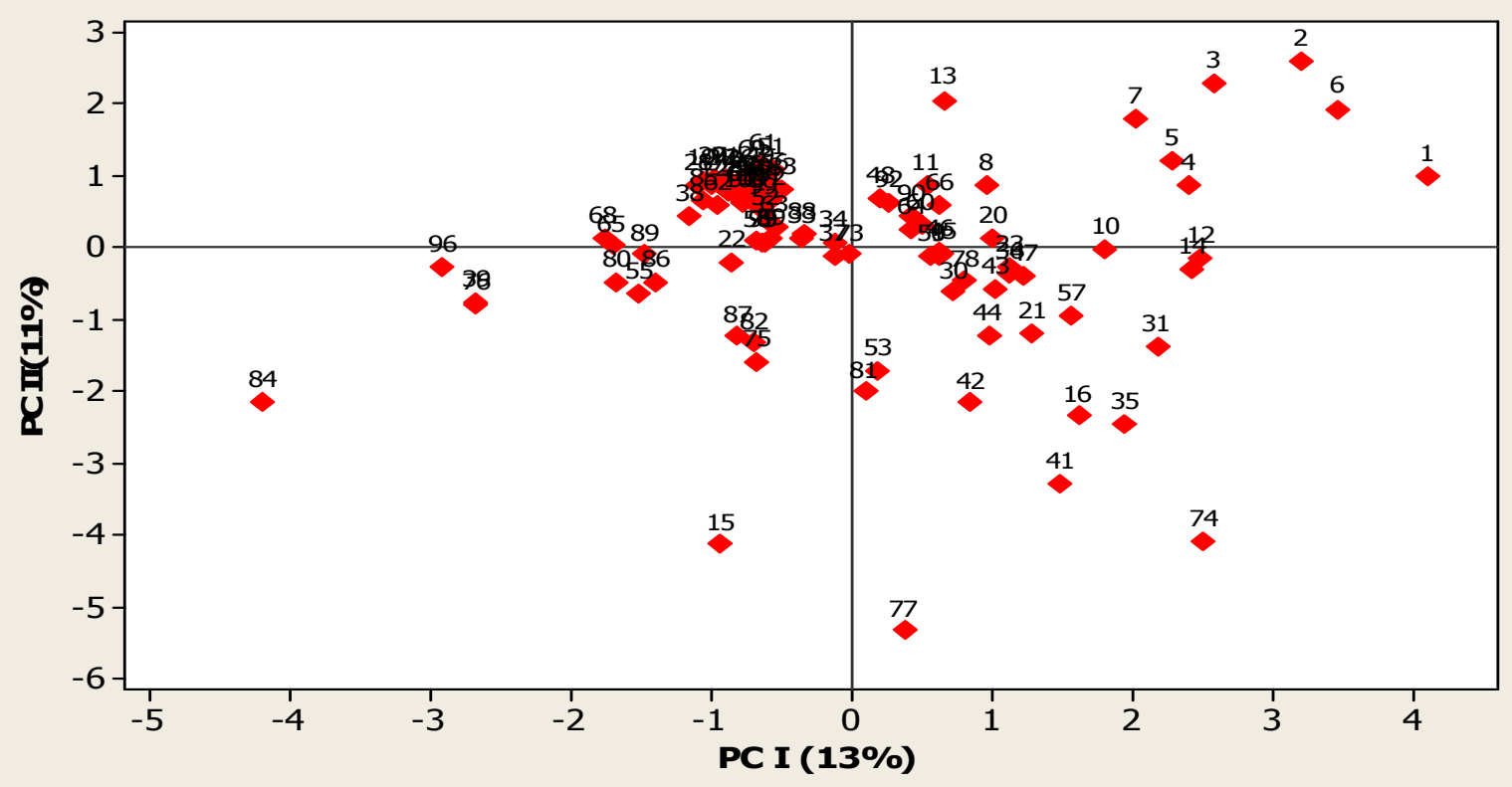

Figure 2. Groups formed from the first (PCI) principal components for 100 taro accessions collected from south and southwest Ethiopia by using 17 qualitative traits. 
To assess the score of individual accessions PC1 and PC2 were plated in (Figure 2). The accessions 1, 2, 3, 4, 5, 6,7 , and 12 occupied the right top corner of the plot indicating the higher scores for both PC1 and PC2. Nevertheless, accession 13 occupied the middle top position of the plot indicating relatively medium score for $\mathrm{PC} 1$ and relatively higher score for PC2. Most of accessions in this study fall in the central quadrant of the plot and have high loadings on the first and second principal components (Table 1). Characterization based on qualitative traits; enable the separation of accessions in different groups which represent accessions present in different geographical areas of the country. Consequently, this result can give picture on identifying characters that are helpful for characterize taro. Therefore, the result permits the selection of maximum descriptors for characterizing taro found in the country based on qualitative traits.

\subsection{Frequency Distribution of Major Qualitative Traits}

\subsubsection{Vegetative Characters}

A wide range of variation was observed among the 100 taro accessions investigated with regard to qualitative agromorphological characters assessed. Major phenotypic characters showed variation in most important foliar and subterranean plant parts. However, in some characters such as leaf vain pattern Leaf blade color variegation and root color were similar for all accessions. (Table 2).

\subsubsection{Leaf Characteristics}

Out of the seven phenotypic classes of this character, horizontal and cup-shaped lamina was found predominant leaf position among taro accessions. Of the tested cultivars, $73.0 \%$ exhibited horizontal leaf surface and $27.0 \%$ comprised cup-shaped leaf position. Three dominant leaf blade colors was observed among taro cultivars, these are $24.0 \%$, $65.00 \%$ and $11 \%$ of the accessions exhibited yellow green and pink respectively. With respect to leaf blade margin the taro accessions fall into two categories; undulated (83\%) and sinuate $(16 \%)$. In line with this, [12], who identified accessions with undulate leaf blade margin in southern Ethiopia. In this study, all taro accessions have Y- shaped leaf vain pattern, while, blade color of the accessions ranged from pink $(11.00 \%)$ to green $(65.00 \%)$.

\subsubsection{Petiole Characteristics}

A variation among taro accessions based on petiole was observed. In this study, $50.0 \%, 6.00 \%$ and $44.0 \%$ of accessions expressed yellow, green and purple petiole junction. Similarly, $64.0 \%$ and $17.0 \%$ ) of accessions had green and light green petiole color. Furthermore, $56.0 \%$ and $44.0 \%$ of the total accessions showed small and medium petiole junction pattern. This also indicated that there is a wide range of variation in different traits of Colocasia esculenta in the country. Therefore, there need to consideration effort for conservation and research on taro (Table 2).

\subsubsection{Tuber Characteristics}

Corm cortex color of the accessions ranged from brown (26.0\%), purple (11.0\%) and blackish (63.0\%). [12] recognized wide variations for corm cortex color cream to white in fried taro cultivars. Furthermore, in this study, it was observed that corm skin surface of Colocasia esculenta varied from smooth $(26.00 \%)$ to fibrous $(74.00 \%)$. Corm flesh color also varied from accession to accession as pink with white $(45.00 \%)$ and white $(55.0 \%)$ and accession have round $(47.00 \%)$, conical $(48.00 \%)$ and cylindrical $(5.0 \%)$ corm shape (Table 2). In line with this, similar agreement with works of [13 and 14] who reported that there is a wide range of variability of tubers among Dioscorea and Colocasia species in Ethiopia. Furthermore, similar result was reported by [1] in cassava, [12] in taro and [15] in Plectranthus edulis. However, in this study, all accessions have brown in its root color.

\subsection{Agro-Morphological Diversity of Taro Based on Quantitative Characters}

\subsubsection{Analysis of Variance}

The analysis of variance of quantitative characters showed significant difference $(\mathrm{P}<0.01)$ among the accessions for 2 of the 13 characters examined indicating the existence of substantial amount of variability for the characters (Table 3 ). The characters that manifested significant difference are petiole length and maximum horizontal distance. On the other hand, non-significant difference was observed among the accessions for leaf length, leaf width, basal ring length, plant height, number of sucker/plant, number of tuber/hill, tuber length, tuber diameter, tuber fresh weight/plot and tuber dry weight/plot revealed that the contribution of these characters to the variability was minimum.

Table 3. Analysis of variance for 13 quantitative characters of Collocasia esculenta accessions grown at Jimma in 2011.

\begin{tabular}{llllll}
\hline \multicolumn{5}{c}{ Mean squares } \\
\hline No & Characters & Accessions & Error & $\mathrm{R}^{2}$ & CV (\%) \\
\hline 1 & Leaf Length(m) & 42.78 & 56.74 & 0.74 & 18.59 \\
2 & Leaf width(m) & 28.03 & 38.75 & 0.63 & 24.14 \\
& & & & & \\
3 & $\begin{array}{l}\text { Number of } \\
\text { active leaves/plant }\end{array}$ & $45.61^{*}$ & 32.45 & 0.68 & 36.23 \\
4 & Petiole length(cm) & $126.0 * * *$ & 67.49 & 0.67 & 15.67 \\
5 & Basal ring length(cm) & 126.36 & 134.88 & 0.48 & 20.06 \\
6 & $\begin{array}{l}\text { Maximum } \\
\text { horizontal distance(m) }\end{array}$ & $0.047^{* * *}$ & 0.027 & 0.64 & 17.02 \\
7 & Plant height(m) & 0.082 & 0.073 & 0.53 & 27.48 \\
8 & Number of sucker/plant & 6.51 & 6.09 & 0.54 & 39.32 \\
\hline
\end{tabular}




\begin{tabular}{llllll}
\hline \multicolumn{7}{c}{ Mean squares } \\
\hline No & Characters & Accessions & Error & $\mathrm{R}^{2}$ & CV (\%) \\
\hline 9 & Number of tuber/hill & 6.21 & 6.86 & 0.49 & 34.36 \\
10 & Tuber length & 2.13 & 2.15 & 0.5 & 12.60 \\
11 & Tuber diameter & 95.07 & 84.95 & 0.52 & 14.70 \\
12 & Tuber fresh weight & 0.08 & 0.07 & 0.54 & 34.77 \\
13 & Tuber dry weight & 17.56 & 17.31 & 0.50 & 14.58 \\
\hline
\end{tabular}

\subsubsection{Genetic Variability, Estimation of Heritability and Genetic Advance}

The estimates of genotypic and phenotypic variance, broad sense heritability, genetic advance and genetic ad- vance in percentages of means are indicated in Table 4. The highest genetic variance was observed for petiole length $(\mathrm{cm})$, leaf length $(\mathrm{cm})$ and petiole basal ring length $(\mathrm{cm})$. The larger proportion of phenotypic variance on these traits were contributed from the genotypic variance then the environment variance and hence, it can be exploited in breeding program, The magnitude of genotypic variance was higher than phenotypic variance as the latter is a component of the former. The phenotypic variance $\left(\sigma_{p}^{2}\right)$ is the sum of environmental variance $\left(\sigma_{\mathrm{e}}^{2}\right)$, genetic variance $\left(\sigma_{\mathrm{g}}^{2}\right)$ and their interaction $\left(\sigma_{\text {ge }}^{2}\right)$. However, the phenotypic and genotypic variance values can be used for comparing degrees of variability since different traits have different means. For this reason genotypic and phenotypic coefficient of variations were used.

Table 4. Estimates of components of variance, PCV, GCV, heritability and genetic advance for 13 quantitative characters of Colocasia esculenta grown at Jimma, 2011

\begin{tabular}{|c|c|c|c|c|c|c|c|}
\hline Traits & $\sigma_{\mathrm{g}}^{2}$ & $\sigma_{p}^{2}$ & PCV & GCV & $\begin{array}{l}\text { Heritability } \\
(\%)\end{array}$ & Genetic advance & $\begin{array}{l}\text { GAM } \\
(\%)\end{array}$ \\
\hline LL & 5.398 & 42.599 & 15.843 & 5.639 & 12.67 & 1.70 & 4.135 \\
\hline LW & 0.806 & 22.865 & 17.461 & 3.277 & 3.52 & 0.34 & 1.267 \\
\hline NAL & 6.235 & 25.979 & 33.510 & 16.417 & 24.00 & 2.52 & 16.568 \\
\hline PL & 29.669 & 97.139 & 18.809 & 10.394 & 30.54 & 6.20 & 11.834 \\
\hline Ba.RL & 4.453 & 130.741 & 19.751 & 3.645 & 3.41 & 0.80 & 1.385 \\
\hline MHD & 0.003 & 0.029 & 17.986 & 5.460 & 9.22 & 0.03 & 3.414 \\
\hline PH & 0.005 & 0.078 & 28.366 & 7.008 & 6.10 & 0.03 & 3.566 \\
\hline $\mathrm{NSu}$ & 0.109 & 5.274 & 34.839 & 5.009 & 2.07 & 0.09 & 1.483 \\
\hline NT/hil & 0.456 & 6.210 & 32.425 & 8.782 & 7.34 & 0.37 & 4.900 \\
\hline TL & 0.010 & 2.144 & 12.574 & 0.854 & 0.46 & 0.13 & 0.119 \\
\hline TDi & 4.319 & 89.463 & 15.119 & 3.321 & 4.83 & 0.94 & 1.503 \\
\hline TFW & 0.004 & 0.082 & 35.656 & 8.266 & 5.37 & 0.03 & 3.947 \\
\hline TDW & 0.041 & 17.263 & 14.614 & 0.715 & 0.24 & 0.20 & 0.072 \\
\hline
\end{tabular}

$L L=$ Leaflength LW= leaf width $; A L=$ Number of active leaves, Pl= Petiole length Ba.RL = Basal ring length, MHD= Maximum horizontal distance, $P H=$ Plant height, Nsu= Number of sucker/plant, NT/hil= Number of tuber/hill, TL=Tuber length, TDi=Tuber diameter, TFW=Tuber fresh weight and TDW=Tuber dry weight.

The estimation of GCV and PCV for the fresh tuber yield $(\mathrm{kg} / \mathrm{plot})$, petiole length $(\mathrm{cm})$, number of active leaves/plant, number of sucker/plant, plant height $(\mathrm{cm})$, number of tuber/hill, and maximum canopy distance (m) exhibited relatively higher GCV and PCV (Table 4). The magnitude of phenotypic coefficient of variation (12.57-35.65\%) in the present study was slightly wider than GCV $(0.715-16.417)$ suggesting that environmental factors have high contribu- tion to the observed variation among taro accessions. In general, this study revealed that the taro accessions used in this study were phenotypic ally and genotypic ally diverse. This indicates the existence of large diversity in taro for quantitative characters. This is similar results was observed in [12] on 7 accessions of taro in southern Ethiopia.

Heritability estimates ranged from $0.24 \%$ for tuber dry weight to $30.54 \%$ for petiole length per plant (Table 4). 
Heritability estimates for petiole length $(\mathrm{cm})$, leaf length (cm), number of active leaves/plant, maximum canopy/horizontal distance/plant and number of tuber/ hill were relatively higher than other traits. Relatively higher heritability coupled with high genetic advance and genetic advance in percentage of means was exhibited for petiole length and number of active leaves/plant reflecting the chance that these traits are the basis for selection and further improvement work in taro.

\subsection{Path Coefficient Analysis}

Path coefficient analysis at genotypic level showed that tuber fresh weight had a maximum direct positive effect on maximum horizontal distance $(\mathrm{p}=2.810)$ followed by leaf width $(\mathrm{p}=2.800)$. Number of tuber/hill also had positive indirect effect on tuber fresh weight through most of the traits except through basal ring length, plant height and tuber diameter. (Table 5). On the other hand, the maximum negative direct effect of number of tuber/hill on tuber fresh weight may be explained by the fact that number of tuber/hill may contain a lower percentage of water. Tuber yield components seem to have competitive effect with tuber fresh weight at path coefficient analysis level and have to be selected against.

Table 5. Genotypic direct (bold and underlined) and indirect effects of some characters on tuber. fresh weight of Collocasia esculenta.

\begin{tabular}{|c|c|c|c|c|c|c|c|c|c|c|c|c|c|}
\hline Traits & $\mathbf{L L}$ & $\mathbf{L W}$ & NAL & PL & BaRL & MHD & PH & NSu & NT/hill & TL & TDi & TDW & rg \\
\hline LL & -1.12 & 1.96 & 1.19 & -1.74 & -1.53 & 1.12 & -1.23 & -1.50 & 1.37 & 1.04 & -1.35 & -1.33 & 0.17 \\
\hline LW & -2.11 & $\underline{2.80}$ & -1.28 & 1.41 & -1.77 & 1.72 & 1.66 & -1.78 & 1. 29 & 1.36 & -1.31 & 1.86 & 0.01 \\
\hline NAL & 1.77 & -2.81 & -1.27 & 2.17 & 0.55 & 0.15 & -0.54 & -1.28 & 0.06 & 0.76 & -0.38 & -1.68 & 0.16 \\
\hline PL & 1.11 & 1.69 & 1.25 & $\underline{-2.66}$ & 1.96 & 4.31 & -1.58 & -1.47 & 0.15 & 0.41 & 1.28 & -1.67 & -0.02 \\
\hline BaRL & -1.40 & 1.26 & -1.34 & -1.17 & -1.35 & 1.89 & 1.99 & -1.93 & -1.45 & 1.32 & -1.05 & -1.43 & 0.12 \\
\hline MHD & 1.84 & -1.71 & -0.18 & -1.68 & 1.77 & $\underline{2.81}$ & -1.85 & -0.95 & 0.11 & -1.01 & 1.86 & 0.90 & 0.02 \\
\hline PH & 2.45 & 2.01 & -0.35 & -1.09 & -0.79 & 1.63 & $\underline{-2.10}$ & -0.52 & -0.72 & -0.69 & 0.45 & -1.50 & 0.08 \\
\hline $\mathrm{NSu}$ & 1.17 & -1.20 & -1.67 & -1.35 & 1.65 & 2.34 & -2.32 & $\underline{1.14}$ & 0.15 & -0.90 & 1.62 & -1.93 & 0.06 \\
\hline NT/hil & 1.44 & -1.88 & -0.26 & -1.13 & -1.53 & 0.39 & 1.69 & -0.21 & $\underline{-0.78}$ & -0.62 & -0.76 & -1.26 & 0.15 \\
\hline $\mathrm{TL}$ & -2.93 & 2.20 & 1.42 & 1.25 & -1.37 & 1.96 & -1.38 & -1.30 & 0.47 & $\underline{1.03}$ & -1.75 & 1.87 & -0.08 \\
\hline TDi & -2.93 & 1.16 & 1.26 & -1.28 & -1.44 & 1.27 & -1.30 & -1.99 & -0.59 & 1.92 & $\underline{0.99}$ & 1.80 & 0.05 \\
\hline TDW & 1.77 & 2.18 & -1.11 & -1.06 & 1.86 & -0.51 & -1.77 & -1.12 & 1.16 & 1.97 & -0.96 & $\underline{-1.94}$ & -1.00 \\
\hline
\end{tabular}

Residual effect $=0.29 . L L=$ Leaf length; $L W=$ leaf width; $N A L=$ Number of active leaves, $B a R L=$ Basal ring length, $M H D=M a x i m u m$ horizontal distance, $\mathrm{PH}=$ Plant height, $N \mathrm{Su}=$ Number of sucker, NT/hil= Number of tuber/hill, TL=Tuber length, TDi=Tuber diameter, $T F W=$ Tuber fresh weight and TDW=Tuber dry weight.

With the same analogy, number of tuber/hill exerted negative direct and indirect effect on fresh tuber yield and basal ring length $(\mathrm{cm})$, tuber diameter $(\mathrm{cm})$, tuber dry weight (kg/plot) and petiole length (cm). [16 and 17], also reported similar direct positive effect on number of tubers/roots per plant on potato and cassava respectively. The residual effect (0.290) is relatively low indicating that the characters considered in this analysis successfully explained variation existing in the accession of taro.

Therefore, selection based on these characters is efficient to maximize fresh tuber yield as well as future improvement program of taro.

\section{References}

[1] Amsalu Nebiyu. 2003.Characterization and divergence analysis in cassava (Manihot esculenta Cranz) Genotypes at Jimma. MSc thesis, Alemaya University, Ethiopia.
[2] Tewodros Mulualem. 2011. Exploiting indigenous knowledge for selection and classification of Aerial yam (Dioscorea bulbifera( L.)) accessions in south and southwestern Ethiopia. Presented the 14 th Crop Science Socity of Ethiopia, 28-29 April, 2011, Addis Ababa, Ethiopia.

[3] Edossa Etissa. 1996. Root and Tuber Crops: Potential as food crops in the humid areas of Ethiopia. In: IAR News letter of Agric. Res. 2 (1). IAR, A.A, Ethiopia.

[4] Edwards SB. 1991. Crops with wild relatives found in Ethiopia. In: Engles JMM.

[5] Tewodros Mulualem. 2008. Morphological characterization and preliminary evaluation of Aerial yam (Dioscorea bulbifera) collected from south and south-western Ethiopia. MSc thesis, Awassa University, Ethiopia.

[6] IPGRI/IITA. 1999. Descriptors for taro (Collocasia spp.). International Institute for Tropical Agriculture, Ibadan, Nigeria / International Plant Genetic Resources Institute, Rome, Italy. 
[7] Gomez K.A., and A.A. Gomez. 1984. Statistical Procedures for Agricultural Research. 2nd ed. John Wiley and Sons., inc., New York. 680 pp.

[8] SAS Institute 2008. Statistical Analytical Systems SAS / STAT user's guide version 9(1) cary NC :SAS institute inc.

[9] Allard R.W. 1960. Principles of Plant Breeding. John Wiley and Sons Inc. New York. 485 p.

[10] Dewey D.R. and Lu, K. H. 1959. A correlation and path coefficients analysis of components of crested wheat grass seed production. Agron. J., 51:515-518.

[11] Mahalanobis, P.C. On the Generalized Distance in Statistics. Proc. Natl. Scence. India B. 2: 49- 55, 1936.

[12] Yared Dagne. 2007. Studies on indigenous production and evaluation of landrace taro clones (Colocasia esculenta L. (Schott) at Dalbo watershed, Wolaita, South Ethiopia. M.Sc. thesis, Presented to School of Graduate Studies, Hawassa University, Awassa.
[13] Muluneh Tamiru. 2006. Assessing diversity in yam (Dioscorea spp.) from Ethiopia based on morphology, AFLP marker and tuber quality, and farmers' management of landraces. Ph.D. thesis, George -August University. Germany.

[14] Asfaw K. 2006. Characterization and divergence analysis of some Ethiopian taro (Collocasia esculenta (L.) accessions M.Sc thesis, Alemaya University, Ethiopia.

[15] Woyessa Garedew. 2006. Morphological characterization and divergence analysis of Plectranthus edulis (Vatke) Agnew collection in Ethiopia. M.Sc. thesis, Presented to School of Graduate Studies, Hawassa University, Awassa.

[16] Rubaihayo P.R., Whyte J.B.A., Dixon, A.G.O., Osiru, D.S.O. 2001.Inter- relationships among traits and path analysis for yield components of cassava: a search for storage root yield indicators, African crop science, J. 9(4).

[17] Pandey S.K., Singh S.V. and Manivel, P. 2005. Genetic variability and causal relationship over seasons in potato. Crop Res. 29(2), 277-281. 